\title{
Noma: neglected, forgotten and a human rights issue
}

\section{Leila Sroura,*, Klaas W. Marck ${ }^{b}$ and Denise Baratti-Mayerc}

\author{
${ }^{a}$ Health Frontiers, Bhan Tat Khao, Vientiane, Laos; ${ }^{b}$ Dutch Noma Foundation, De Pôlle 24, 9084BT Goutum, \\ The Netherlands; ' GESNOMA (Geneva Study Group on Noma), Service of Plastic and Reconstructive Surgery, \\ Geneva University Hospitals, Geneva, Switzerland
}

*Corresponding author: Tel: +856 20 55797111; E-mail: leila@butterflychildren.org

Received 2 December 2014; revised 22 December 2014; accepted 23 December 2014

\begin{abstract}
Noma, an orofacial gangrene and opportunistic infection, affects primarily malnourished children living in extreme poverty. Neglected, forgotten, unknown by most health workers, noma results in death, disfigurement and disability of some of the world's most vulnerable children. Noma is a biological indicator of multiple human rights violations, including the right to food. International support and national attention in countries with noma are lacking. The end of neglect of noma can lead to the elimination of this horrific childhood disease.
\end{abstract}

Keywords: Cancrum oris, Developing countries, Human rights, Malnutrition, Neglected diseases, Noma

Noma is a facial gangrene mainly occurring in malnourished children aged $1-5$ years, living in extreme poverty. ${ }^{1}$ Besides malnutrition other predisposing factors are measles, malaria, HIV and the presence of acute necrotizing gingivitis. ${ }^{1,2}$ Noma is an opportunistic infection, associated with an imbalance of microorganisms. In the past fusiform and spirochaetal microorganisms, identified as Fusiformis fusiformis and Borrelia vincenti, have been identified between gangrenous and healthy tissue. ${ }^{3}$ This resulted in the historical synonym fusospirochaetal gangrene. However, it still is unknown which microorganisms play a role in initiating and expanding this quickly spreading, but non-contagious gangrene. ${ }^{4}$ The clinical course of noma starts with facial edema, extreme halitosis and hypersalivation (Figure 1A). Intraoral inspection may reveal a painful red spot or a necrotizing gingivitis/stomatitis. Within a few days, a bluish discoloration appears in the edematous region, after which the skin breaks down over the underlying extensive necrosis. After separation of the gangrenous tissue, a large hole results often showing devitalized bone that will sequester at a later stage (Figure 1B). If the patient survives, natural healing frequently leads to a mutilated face with severe functional impairments like trismus or ankylosis of the mandible, drinking, eating and speech problems, oral incontinence, and sequelae often results in social isolation (Figure $1 \mathrm{C}$ ).

Noma is an old companion of mankind. In previous centuries the disease has been described commonly in European countries and the USA. ${ }^{5}$ It disappeared from these countries due to increased welfare, enabling even the poorest to adequately feed their children. The disease has been forgotten and disappeared almost completely from modern medical textbooks. However, noma is still present in countries where extreme poverty and malnutrition are prevalent. Global incidence is not well known because health statistics in less privileged countries do not include noma as a cause of death. Incidence estimates vary between 40000 and 140000 annually. ${ }^{6}$ It is assumed that noma is mainly found in what is called the world's noma belt: the part of Africa that lies directly sub-Saharan from Senegal in the west to Ethiopia in the east. In Central and more Southern African countries noma is not uncommon, while more incidental cases have been described in Southeast Asia and in South America. ${ }^{7}$ It is enigmatic that on the Indian subcontinent, where child mortality in absolute numbers is very high, noma is more or less absent in medical literature.

The mortality rate is not well known. Historical data indicate that $80-90 \%$ of noma patients die due to sepsis. Mortality decreases significantly to around $10-20 \%$ when the child receives medical attention at an early stage of the disease and is treated with oral antibiotics. Moreover, nutritional support is essential, treatment of vitamin deficiencies, concomitant diseases, and sometimes parenteral fluids, IV antibiotics and blood transfusion are needed. However, most noma patients do not have access to healthcare. The percentage of children with noma who receive medical treatment is estimated to be $10 \%$, which the authors consider optimistically high. ${ }^{8} \mathrm{~A}$ sound approach for reconstructive surgical rehabilitation of noma survivors has been described by Tempest half a century ago and further developed by many others. ${ }^{1}$ The authors estimate that only $2-5 \%$ of noma survivors receive any treatment, mainly provided by small NGOs.

The most prominent feature of this brief picture of noma is omnipresent neglect. This facet of the disease was recognized long ago by Arnoldus Bootius who included noma in his book (the first one about neglected diseases) 'Observationes Medicae de Affectibus Omissis', published in London in 1649. The present neglect encompasses not only the social isolation that takes place due to the often mutilated face and its cultural implications (bad omens related to bad spirits etc.), but also the lack of access to both acute medical and later surgical rehabilitation. 

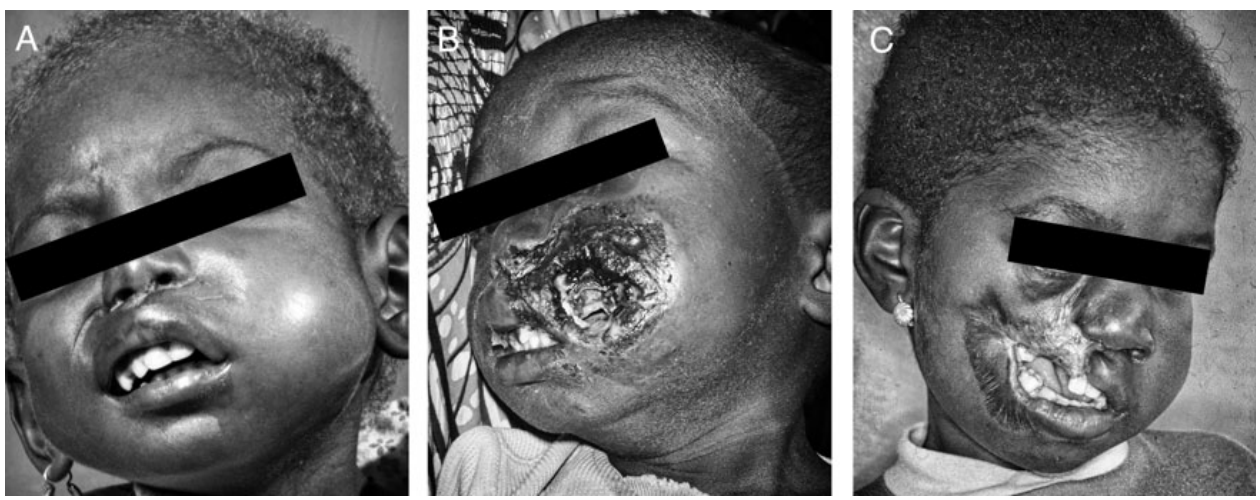

Figure 1. The different stages of noma. A. The first stage of noma: facial edema, often accompanied by extreme halitosis and hypersalivation. Gangrene or its extension can be prevented by administration of antibiotics at this stage. B. The second stage of noma: within a few days gangrene has developed with the hole in the skin as 'the tip of the iceberg' of the necrotic tissue. Administration of antibiotics and other treatment increase survival chance significantly. C. The third stage of noma: often a mutilated face due to tissue loss and wound contracture with impairments such as trismus or ankylosis of the mandible, eating, drinking and speech problems and social isolation. Surgical rehabilitation may relieve these impairments.

Medical science including microbiology, public health and epidemiology, have shown a lack of interest. In the last half century few microbiological studies have been done on noma. Countries where noma is prevalent do not include the disease in their health statistics, nor is it included in Western-based medical teaching programs. With few exceptions, their governments have shown little interest in the disease and its victims. Health policy makers prefer to introduce advanced and expensive facilities, such as dialysis centers or open heart surgery in the capital city, for which self-interest is a plausible explanation. WHO has not developed any effective programs aiming at collecting epidemiologic data, early detection or treatment. None of the editions of the Global Burden of Disease have paid attention to this affection and noma does not appear on any list of neglected tropical diseases (NTDs). A recent estimate of the global burden of disease from noma resulted in 1.1 million daily-adjusted life years, even if a best case scenario was assumed, which is high as compared with many NTDs. ${ }^{9,10}$ The conclusion that we can draw is that noma belongs to the special category of 'neglected-neglected diseases'.

Noma, an indicator of extreme poverty and insufficient food, is evidence of human rights violations, as advocated by Jean Ziegler, a Swiss sociologist and member of the Advisory Committee of the UN Human Rights Council (2008 to 2012). His efforts led to the adoption of resolution 19/7, 'The right to food', by the Human Rights Council in 2012, with children affected by noma the prime example of a violation of this right. Noma is evidence of multiple human rights violations, including the right to clean water and sanitation, healthcare and adequate housing. Noma survivors are often excluded from school and jobs and without access to surgical rehabilitation, often are unable to marry, or to simply 'have a life'.

We appeal that noma be added to the list of NTDs, for more research on its epidemiology and pathogenesis, in particular the microbiological aspects, for inclusion of the disease in medical teaching programs in countries where the disease is prevalent and for surveillance programs in areas where noma is a more or less a common killer. Humanitarian programs for surgical rehabilitation of noma survivors need further support. It is high time that we face 'the face of poverty'.
Authors' contributions: MLS, KWM and DB-M wrote and revised the manuscript. All authors read and approved the final manuscript. MLS is the guarantor of the paper.

Funding: None.

Competing interests: None declared.

Ethical approval: Not required.

\section{References}

1 Tempest MN. Cancrum oris. Brit J Surg 1966;53:949-69.

2 Chidzonga MM, Mahomva L. Noma (cancrum oris) in human immunodeficiency virus infection and acquired immunodeficiency syndrome (HIV and AIDS): clinical experience in Zimbabwe. J Oral Maxillofac Surg 2008;66:475-85.

3 Emslie RD. Cancrum oris. The Dental Practitioner 1963;13:481-95.

4 Baratti-Mayer D, Pittet B, Montandon D et al. Noma: an "infectious" disease of unknown aetiology. Lancet Infect Dis 2003;3:419-31.

5 Marck KW. A history of noma, the "Face of Poverty". Plast Reconstr Surg 2003;111:1702-7.

6 Fieger A, Marck KW, Busch R, Schmidt A. An estimation of the incidence of noma in north-west Nigeria. Trop Med Int Health 2003;8:402-7.

7 Wertheim HFL, Horby P, Woodall JP, editors. Atlas of Human Infectious Diseases. Chichester: John Wiley \& Sons Ltd; 2012.

8 Enwonwu CO, Falkler WA Jr, Phillips RS. Noma (cancrum oris). Lancet 2006;368:147-56.

9 Haesen S, Furst F, Utzinger J. Noma: epidemiology and global burden of a neglected disease. Poster at the joint conference of the International Society for Environmental Epidemiology (ISEE), the International Society of Exposure Science (ISES) and the International Society of Indoor Air Quality and Climate (ISIAQ): 2013 Aug 19-23; Basel, Switzerland.

10 Hotez PJ, Alvarado M, Basanez MG et al. The global burden of disease study 2010: interpretation and implications for the neglected tropical diseases. PLoS Negl Trop Dis 2014;8:e2865. 